
\title{
25 Research Soure \\ Risk and protective factors for acute mountain sickness: a meta-analysis
}

\section{Sergio Recalde ( $\nabla$ srecalde@unav.es )}

Universidad de Navarra https://orcid.org/0000-0002-9328-9725

\section{Leire Alargunsoro}

Universidad de Navarra Facultad de Medicina

\section{Fermin I. Milagro}

Universidad de Navarra

\section{Ricardo lbañez}

Universidad de Navarra

\section{Andrea Villegas}

Universidad de Navarra

Victor J. Sáez

Universidad de Navarra

\section{Manuel Cires}

Universidad de Navarra

Laura Garcia-Garcia

Universidad de Navarra

\section{Research}

Keywords: Acute Mountain Sickness, high altitude, Hackett's Score, Lake Louise Score

Posted Date: August 23rd, 2021

DOl: https://doi.org/10.21203/rs.3.rs-812272/v1

License: (c) (i) This work is licensed under a Creative Commons Attribution 4.0 International License.

Read Full License 
Title: Risk and protective factors for acute mountain sickness: a meta-analysis.

Authors: Leire Alargunsoro ${ }^{1,2}$ Fermin I. Milagro ${ }^{2,3,4}$, Ricardo Ibañez ${ }^{2,5}$, Laura GarciaGarcia $^{2}$, Andrea Villegas ${ }^{2}$, Victor J. Sáez ${ }^{2}$, Manuel Cires ${ }^{2,6}$, Sergio Recalde ${ }^{2,4,7}$. Affiliations:

1; Medicine Faculty, Universidad de Navarra, Pamplona, Spain 2; University of Navarra Mountain Club. Sport Service. Universidad de Navarra. Pamplona, Spain.

3; Department of Nutrition, Food Science and Physiology/Centre for Nutrition Research, Faculty of Pharmacy and Nutrition, University of Navarra, Pamplona, Spain 4; IdiSNA, Navarra Institute for Health Research, Pamplona 31008, Navarra, Spain.

5. Department of Environmental Biology, University of Navarra, Pamplona, Spain.

6. Department of General and Digestive Surgery. Navarra Health Service. Estella, Spain. 7; Experimental Ophthalmology Laboratory, Universidad de Navarra, Pamplona, Spain. 


\section{Abstract}

Background: Currently, many people reach 3000-meter summits or greater. Some of these climbers suffer from acute mountain sickness (AMS), while others remain symptom-free. Some risk factors for AMS are well defined, such as lack of pre-acclimatization, rapid ascent, maximum altitude, and resilience at low altitude. However, there are other poorly described associated factors, such as sex, age, smoking, body mass index, medication use, and awareness or history of AMS. The objective of this meta-analysis was to establish the risk and protective factors associated with AMS.

Methods: PubMed, UNIKA, and Scopus databases were searched in July 2020 for articles to include in the analysis. AMS was separately evaluated by the Lake Louise Score (LLS) and Hackett's Score (HS). After screening and application of eligibility criteria, 14 articles were included in the meta-analysis (LLS $=12$ and HS $=2$ ).

Results: A total of 18,938 participants were included in the study with 17,450 in the LLS group and 1,488 in the HS group. In the LLS group, smoking (odds ratio [OR] 0.76 [0.63-0.92]; $\chi^{2}=$ $10.3 ; I^{2}=61.2 \%$ ), history of AMS (OR 1.16 [1.03-1.32]; $\chi^{2}=12.2 ; 1^{2}=67 \%$ ), altitude preexposure (OR 0.68 [0.5-0.91]; $\left.\chi^{2}=22.21 ; I^{2}=82 \% ; \tau^{2}=0.06\right)$, and maximum altitude (OR 2.01 (1.07-3.77) $\left(\chi^{2}=19.15 . I^{2}=89.6 \% . \tau^{2}=0.26\right)$ were statistically significant. In the HS group, age $>35$ years (OR 0.72 [0.52-0.99]; $\chi^{2}=2.14 ; I^{2}=6.7 \%$ ) and a history of AMS (OR 8.2 [3.28-20.54]; $\chi^{2}=3.7 ; 1^{2}=73 \% ; \tau^{2}=0.32$ ) were found to be statistically significant.

Conclusions: This study suggests that younger age, non-smoking, history of AMS, nonacclimatization, and hiking to a high maximum altitude $(>2500 \mathrm{~m})$ increases the possibility of suffering from AMS.

Keywords: Acute Mountain Sickness, high altitude, Hackett's Score, Lake Louise Score. 


\section{Background}

Nowadays, people travel increasingly around the world; therefore, the number of tourists who want to have a high-altitude hiking experience is increasing. This leads to more accidents, such as falls, fractures, sprains, and wounds, with altitudes higher than 2,500 meters. At higher altitudes, there is an increased risk of severe illnesses, including acute mountain sickness (AMS), which can lead to acute cerebral edema.

It is known that the number of non-experienced people hiking at high altitudes is increasing, and most are not aware of the associated risks. For example, there is $26 \%$ less oxygen at an altitude of 2,500 meters and $41 \%$ less oxygen at 4,000 meters compared to that at sea level [1], and due to the decrease in atmospheric pressure, there is a resulting decrease in the partial pressure of oxygen $\left(\mathrm{pO}_{2}\right)$.

Overall, there is a hypoxic situation that leads to physiological reactions while an individual acclimates to a change in altitude. The ventilatory response to hypoxemia may result in hyperventilation. This increase in ventilation also raises the $\mathrm{pO}_{2}$, which induces respiratory alkalosis. Meanwhile, the cerebral blood flow increases, and consequently, the cerebral vasculature may become dilated [2].

When the hypoxemia state lasts for 12-24 hours, the hematocrit and hemoglobin concentrations may increase due to a decrease in plasma volume and hypoxia-stimulated erythropoiesis. After several weeks at the same altitude, the plasma volume and the red cell mass increase, resulting in a total blood volume elevation [3]. This process of getting used to altitude is called acclimatization and is necessary to overcome the need for oxygen. Acclimatization is necessary when hiking mountains higher than 3,000 meters and usually occurs by staying for 2 to 3 weeks at elevation [4], where the individual gets used to the altitude by increasing alveoli ventilation and oxygenation [5].

The problem is that many tourists do not have time to spend more than 2 weeks to allow for acclimatization. As mentioned before, they might not be aware of the risks associated with hypoxemia, and they can develop AMS or other illnesses.

During AMS, the brain and pulmonary system are altered at high altitudes in non-acclimatized people or hypoxic stress overcomes the acclimatization state [6]. AMS symptoms may start when individuals are at an altitude of approximately 2,000 meters, but they are much more frequent above 2,750 meters [7]. The symptoms include headache, dizziness, nausea, vomiting, fatigue, shortness of breath, palpitations, and in the most severe cases, pulmonary or cerebral edema. It is very important to be able to detect these symptoms and to decrease 
the altitude if the symptoms worsen. In fact, most of the symptoms can be treated with a rapid descent to lower altitudes, oxygen, analgesics, and/or antiemetics [7].

AMS can be evaluated using different methods. The Lake Louise Score (LLS) only considers patients' symptoms but other's methods, such as the Hackett score (HS), include physical examination. The LLS is the most widely used method, although it is not the most objective as it is a self-report questionnaire [8].

Several risk factors have been associated with AMS, such as genetic predisposition, rapid altitude ascent, and, since hypoxemia is more severe during sleep, the sleeping altitude. Nevertheless, the associations between AMS and age, sex, or physical fitness are not clear, as the results of different studies are contradictory [9]. Therefore, this study aimed to clarify which risk factors are associated with AMS and to establish the importance of each factor.

\section{Methods}

\section{Search strategy}

First, a searching strategy was set. After several tries the most suitable search terms were 1) risk factors, 2) AMS and 3) prevention, inserting the "AND" connective between. The filters used were English as predetermined language and publication year from 1990 to 2020.

The research was made in three different databases (PubMed, UNIKA and Scopus) on July 2020. The overall results were 174 articles, 63 from PubMed, 57 from Scopus and 54 from UNIKA. After removing the duplicated articles $(n=67)$, the abstracts of each article were read, and 76 were excluded because they did not meet the inclusion criteria.

After reading 31 full-text articles, 16 of them were excluded because they did not meet the inclusion criteria. Nevertheless, when revising the references, another article was excluded because it did not indicate the confidence intervals of the Odds Ratios (Figure 1).

\section{Study selection}

The inclusion and exclusion criteria were established before starting the search. The inclusion criteria were: 1. English language. 2. Studies from 1990 to 2020. 3. Case-control, cohort, or randomised controlled trials. 4. Articles investigating the risk factors that can influence the development of AMS. 5. Studies completed at more than 3,000 meters of altitude, as the risk to suffer AMS below 3,000 meters is minimal. 6. AMS measured by LLS or HS. Symptoms of AMS have been established if LLS had more than 3 points and the HS more than one symptom. 
7. Participants having an ascent more than 300 meters a day or more than 500 meters of total ascent.

\section{Data extraction and synthesis}

The following information was gathered for each study: first author, publication year, diagnostic criteria of AMS, altitude, total number of participants, number of female and male participants, smoking media, age media, BMI (body mass index) media, awareness, acetazolamide use, previous AMS symptoms, pre-exposure in the past 3 months, resilience altitude, maximum altitude reached, duration of ascent, and saturation of $\mathrm{O}_{2}$ [Tables 1 and 2]. The odds ratio $(\mathrm{OR})$, lower confidence interval $(\mathrm{ICl})$ and upper confidence interval $(\mathrm{uCl})$ of each parameter was extracted from the studies. Some of the articles did not indicate the OR directly, but it was calculated from the information given in the studies. Not all the parameters were compared in all the studies, so different data have been extracted from each study.

Previous AMS symptoms are considered when the climber has had another episode when climbing in a different occasion to more than 3,000 meters. The resilience altitude depends on the study, but the minimum altitude has been set at 900 meters. The ascent duration also depends on the study, although the rapid ascent has been set at hiking more than $\mathbf{3 0 0}$ meters of altitude in a day. To conclude, the pre-exposure includes the acclimatization that the climbers have made from two days before the climb to 3 months before.

\section{Assessment of AMS}

AMS can be stratified by different score systems. In this study the LLS and HS have been considered, so that a comparison between them has been made.

LLS is the most widely used score, as it is the easiest to carry out because it is a selfquestionnaire. The LLS considers the most prevalent AMS symptoms, which are 5: headache, gastrointestinal symptoms, fatigue or weakness, dizziness, and sleeping disturbance. Each item is scored from 0 to 3, 0 meaning that the symptom is not present, and 3 that it is severe. The maximum score of the LLS is 15 , and AMS is defined as LLS higher than 3 [10].

On the other hand, the HS consists in a short-structured questionnaire and a physical examination with a maximum score of 18 points. The interview considers several factors, such as: headache, nausea, vomiting, and dizziness, whereas the physical examination determines the periorbital or peripheral edema, respiratory rate, pulmonary rales, and ataxia. If any of these symptoms is positive, the physical examination is repeated by a different examiner. 
Subjects with zero points do not suffer from AMS, those with one or two are moderately affected, and those with three points or more are considered to suffer from AMS [8].

\section{Statistical analysis}

A meta-analysis was performed for each variable using STATA 15.1 (Stata Corp, College Station, TX, USA). A fixed-effect model for relative measures has been applied to aggregate the data at first. Then, a random-effect model has been applied to the meta-analysis that had a high heterogeneity $\left(I^{2}>70 \%\right)$. OR has been used to assess the binary outcomes variables. Heterogeneity has been analysed by chi squared $(\mathrm{Q})$ and $\mathrm{I}$-squared $\left(\mathrm{I}^{2}\right)$ results, and the tausquared $\left(\mathrm{Tau}^{2}\right)$ results have been used to study the variance on the meta-analysis were a random-effect analysis has been applied. At last, the presence of publication bias has been estimated by the meta-funnel plot and the Egger test. 


\section{Results}

The data extracted from the studies are presented in Tables 1 and 2. Table 1 shows the data from the studies that used the LLS to assess AMS, whereas Table 2 shows the data from studies that used HS to assess AMS. In total, there were 14 articles from 2003 to 2020 that used the LLS for assessment, with a maximum altitude of 5,895 meters and an average participant age of 34.77 years ( $n=17,450$ climbers; 2,774 females and 14,425 males). Two studies used the HS, one from the year 2011 and the other from 2014, with a maximum altitude of 5,092 meters and 1,488 participants (626 females and 862 males), with an average age of 42 years.

A meta-analysis was performed for each variable (Table 3). When AMS was measured by the LLS, smoking (OR 0.76 [0.63-0.92]; $\chi^{2}=10.3 ; I^{2}=61.2 \%$ ), history of AMS (OR 1.16 [1.03-1.32]; $\chi^{2}$ $=12.2 ; I^{2}=67 \%$ ), pre-exposure (OR $0.68[0.5-0.91] ; \chi^{2}=22.21 ; I^{2}=82 \% . \tau^{2}=0.06$ ), and maximum altitude (OR 2.01 [1.07-3.77]; $\chi^{2}=19.15 ; I^{2}=89.6 \% ; \tau^{2}=0.26$ ) were statistically significant. Male sex (OR, 0.80 [0.62-1.03]; $\left.\chi^{2}=48.57 ; I^{2}=79.4 \% ; \tau^{2}=0.13\right)$, age $>35$ years (OR $0.98\left[0.93-1.02 ; \chi^{2}=75.70 ; I^{2}=90.8 \% ; \tau^{2}=0.00\right.$ ), high Body Mass Index/obesity (OR 1.49 [0.733.01]; $\chi^{2}=6.75 ; 1^{2}=70.4 \% ; \tau^{2}=0.27$ ), awareness of the risk associated with AMS (OR 0.90 [0.75-1.08]; $\left.\chi^{2}=5.98 ; I^{2}=66.6 \%\right)$, acetazolamide use (OR $0.64[0.40-1.01] ; \chi^{2}=2.21 ; I^{2}=9.6 \%$ ), resilience at high altitudes (OR $0.54[0.29-1.01] ; \chi^{2}=11.26 ; I^{2}=73.4 \% ; \tau^{2}=0.25$ ), and rapid ascent (OR $\left.1.03[0.98-1.08] ; \chi^{2}=31.23 ; I^{2}=84 \% ; \tau^{2}=0.00\right)$ were not statistically significant. 
Table 1. Data selected from the studies measuring acute mountain sickness with the Lake Louise Score [10-21]

\begin{tabular}{|c|c|c|c|c|c|c|c|c|c|c|}
\hline Author & Publication year & $\begin{array}{l}\text { Diagnostic } \\
\text { criteria of } \\
\text { AMS }\end{array}$ & $\begin{array}{l}\text { Altitude } \\
\max .(\mathrm{m})\end{array}$ & Total $\mathbf{n}$ & Female $\mathbf{n}$ & Male $n$ & Smoking $\mathbf{n}$ & $\begin{array}{l}\text { Age } \\
\text { media }\end{array}$ & $\begin{array}{l}\text { Previous } \\
\text { AMS n }\end{array}$ & $\begin{array}{l}\text { Pre- } \\
\text { exposure } n\end{array}$ \\
\hline McDevitt et al. & 2014 & LLS $>3$ & 5,416 & 332 & 169 & 163 & 37 & 35 & & \\
\hline Gonggalanzi et al. & 2016 & LLS>4 & 3,658 & 2,175 & 1,072 & 1,103 & 251 & 37.2 & 590 & 552 \\
\hline Sánchez-Mascuñano et al. & 2017 & LLS>3 & 3,601 & 302 & 156 & 146 & 69 & & & \\
\hline Lang-Yang et al. & 2020 & LLS>3 & 4,095 & 355 & 134 & 222 & & 35.2 & 48 & 27 \\
\hline Wu et al. & 2012 & LLS>3 & 5,010 & 11,182 & 162 & 11,020 & & 29.5 & & \\
\hline Davies et al. & 2009 & LLS>4 & 5,895 & 181 & & & - & 32.3 & - & 0 \\
\hline Vahid-Ziaee et al & 2003 & LLS>3 & 5,671 & 459 & 148 & 311 & & 30 & 85 & \\
\hline Weng et al. & 2013 & LLS>3 & 3,952 & 1,010 & 336 & 674 & & 40 & & 106 \\
\hline Karinen et al. & 2008 & LLS>3 & 5,895 & 112 & 58 & 54 & & & & \\
\hline Mahomed et al. & 2015 & LLS>3 & 5,300 & 89 & 45 & 44 & 14 & 35 & 8 & 54 \\
\hline Maclnnis et al. & 2013 & LLS>3 & 4,380 & 491 & 147 & 344 & 147 & 35 & & \\
\hline Croughs et al. & 2010 & LLS>3 & $>5,000$ & 744 & 381 & 363 & & 36 & 290 & 444 \\
\hline
\end{tabular}

Table 2. Data selected from the studies measuring acute mountain sickness with the Hackett's Score [22,23]

\begin{tabular}{|c|c|c|c|c|c|c|c|c|c|c|}
\hline Author & $\begin{array}{l}\text { Publication } \\
\text { year }\end{array}$ & Diagnostic criteria of AMS & Altitude (m) & Total $n$ & Female $n$ & Male $n$ & Smoking $n$ & $\begin{array}{l}\text { Age } \\
\text { media }\end{array}$ & $\begin{array}{l}\text { Previous } \\
\text { AMS n }\end{array}$ & $\begin{array}{l}\text { Pre- } \\
\text { exposure } n\end{array}$ \\
\hline Santantonio et al. & 2014 & Hackett score $>1-3>4 h$ & 3,961 & 162 & 84 & 78 & - & 40 & - & 27 \\
\hline
\end{tabular}


When comparing the variables from the studies where AMS was measured using the HS, age $>35$ years (OR 0.72 [0.52-0.99]; $\chi^{2}=2.14 ; I^{2}=6.7 \%$ ) and a history of AMS (OR 8.2 [3.28-20.54]; $\chi^{2}=3.7 ;\left.\right|^{2}=73 \% ; \tau^{2}=0.32$ ) were significant. Male sex (OR $1.01[0.54-1.87] ; \chi^{2}, 7.97 ;\left.\right|^{2}=74.9 \%$; $\tau^{2}=0.22$ ), high BMI or obesity (OR $\left.0.97[0.83-1.13] ; \chi^{2}=0.03 ; I^{2}=0.0 \%\right)$, acetazolamide use (OR $0.73[0.09-5.67] ; \chi^{2}=23.21 ; I^{2}=95.7 \% ; \tau^{2}=2.09$ ), a rapid ascent (OR 2.03 [0.6-6.89]; $\chi^{2}=29.83$; $\left.I^{2}=93.3 \% ; \tau^{2}=1.08\right)$, and maximum altitude (OR $\left.1.01[0.90-1.14] ; \chi^{2}=0.61 ; I^{2}=0.0 \%\right)$ were not statistically significant.

Table 3. Results from each meta-analysis

\begin{tabular}{|c|c|c|c|c|}
\hline & \multicolumn{2}{|c|}{ Lake Louise Score (LLS) } & \multicolumn{2}{|c|}{ Hackett's Score (HS) } \\
\hline & OR (uCl-ICl) & Heterogeneity* & OR (uCl-ICl) & Heterogeneity* \\
\hline Sex (Male) & $0.80(0.62-1.03)$ & $48.57 / 79.4 \% / 0.13$ & $1.01(0.54-1.87)$ & 7.97/74.9\%/0.22 \\
\hline Age (>35 years) & $0.98(0.93-1.02)$ & $75.70 / 90.8 \% / 0.00$ & $0.72(0.52-0.99)$ & $2.14 / 6.7 \%$ \\
\hline Smoking & $0.76(0.63-0.92)$ & $10.30 / 61.2 \%$ & - & - \\
\hline High BMI/Obese & $1.49(0.73-3.01)$ & $6.75 / 70.4 \% / 0.27$ & $0.97(0.83-1.13)$ & $0.03 / 0.0 \%$ \\
\hline Awareness & $0.90(0.75-1.08)$ & $5.98 / 66.6 \%$ & - & - \\
\hline Acetazolamide & $0.64(0.40-1.01)$ & $2.21 / 9.6 \%$ & $0.73(0.09-5.67)$ & $23.21 / 95.7 \% / 2.09$ \\
\hline History of AMS & $1.16(1.03-1.32)$ & $12.2 / 67 \%$ & $8.2(3.28-20.54)$ & $3.7 / 73 \% / 0.32$ \\
\hline Pre-exposure & $0.68(0.5-0.91)$ & $22.21 / 82 \% / 0.06$ & - & - \\
\hline Resilience & $0.54(0.29-1.01)$ & $11.26 / 73.4 \% / 0.25$ & - & - \\
\hline Rapid ascent & $1.03(0.98-1.08)$ & $31.23 / 84 \% / 0.00$ & $2.03(0.6-6.89)$ & $29.83 / 93.3 \% / 1.08$ \\
\hline Max. altitude & $2.01(1.07-3.77)$ & $19.15 / 89.6 \% / 0.26$ & $1.01(0.90-1.14)$ & $0.61 / 0.0 \%$ \\
\hline
\end{tabular}

*Heterogeneity chi squared (Q)/I-squared (when the heterogeneity was higher than $70 \%$, a random-effect model was applied)/Tau-squared (random effect model effect applied).In Bold protective and risk significant results.

LLS

The most significant variables are shown in the forest plots (Figures 2 and 3), including smoking, history of AMS, altitude pre-exposure, and maximum altitude.

As shown in Figure 2, smokers have a lower risk of suffering from AMS, with an OR of 0.76 (0.63-0.92). Data from five studies published between 2013 and 2017 were included in this analysis. The study by Gonggalanzi et al. contributed to $60.31 \%$ of the overall weight of the meta-analysis and the analysis showed a high heterogeneity $\left(I^{2}=61.2 \%\right)$.

Regarding previous AMS experience (Figure 3), a previous episode of AMS is a risk factor for developing another episode with an OR of 1.16 (1.03-1.32). Data from five studies published between 2003 and 2020 were included in the analysis. A heterogeneity of $\mathrm{I}^{2}=67 \%$ was calculated in the meta-analysis, and $86.2 \%$ of the weight of the analysis was from the study by Gonggalanzi et al. 
Concerning pre-exposure, a protective effect was revealed in the forest plot with an OR of 0.68 (0.5-0.91) (Figure 4), confirming that the acclimatization process is protective against AMS. Five articles published between 2010 and 2020 were included in the analysis. The article by Croughs et al. contributed $35.98 \%$ of the overall weight in the random effect analysis, and the meta-analysis showed high heterogeneity $\left(1^{2}=82 \%\right)$.

The last LLS forest plot (Figure 5) shows the maximum altitude effect, which is a risk factor for AMS (OR 2.01 [1.07-3.77]). Data from three studies published between 2010 and 2017 were included in the meta-analysis. The analyses showed a high heterogeneity $\left(1^{2}=89.6 \%\right)$ and the article by Croughs et al. contributed to $38.26 \%$ of the weight in the random-effect analysis.

HS

The results from the studies that used the HS to assess AMS were different from those using LLS, as age $>35$ years and a previous history of AMS were statistically significant.

Concerning the effect of age on the incidence of AMS, a protective effect is shown in the forest plot when climbers were $>35$ years old, with an OR of $0.72(0.52-0.99)$ (Figure 6). Three studies published between 2011 and 2014 were included in the analysis. The article by Richalet et al. initially comprised $52.09 \%$ of the overall weight. However, the data were divided and analyzed twice as participants were separated based on acetazolamide use and treated as two independent cohorts; therefore, the overall weight for this article was $89.83 \%$, and the sample had a low heterogeneity $\left(1^{2}=6.7 \%\right)$.

A previous episode of AMS had a risk effect for subsequent AMS, with an OR of 8.72 (5.4513.95) (Figure 7). As in the acetazolamide analysis, only the article by Richalet et al. (2011) was included after dividing the participants into two cohorts, so that the overall weight was entirely due to this article and the sample had high heterogeneity $\left(\mathrm{I}^{2}=73 \%\right)$.

The asymmetry of the funnel plots can be due to heterogeneity, poor methodological quality, artifacts, or chance. As shown in Table 3, most of the meta-analyses showed a high heterogeneity, which could be the reason for the asymmetry according to age, smoking, or pre-exposure (Figures 9, 10, and 11). The other meta-analysis results are also asymmetric, but this could be attributed to the small number of studies included for analysis. 


\section{Discussion}

Globalization has brought about great mobility, with nature and sport tourism as important contributors. At present, rules for making summits accessible only to professional alpinists are changing, leading to increased access to people with little knowledge about mountaineering and its possible dangers, such as altitude sickness. It is important to know the possible dangers and factors that can lead to the development of altitude sickness for prevention and treatment efforts to be effective. Therefore, the meta-analysis conducted in this study aimed to clarify the protective and risk factors for AMS.

Sex (male)

When comparing the variable sex among the selected studies, the LLS fixed-effect metaanalysis shows that being a male is protective compared to being a female, but not for random effects. On the contrary, the HS group meta-analysis of sex did not result in any statistically significant associations. This result could be related to the fact that there were more male participants in the LLS studies; therefore, the effect could have been underestimated in females. In fact, of the total number of participants assessed by LLS in the meta-analysis, $16.13 \%$ were female, whereas in the studies using HS, $42.62 \%$ were female.

Other studies found different results. For example, Hou et al. observed that the prevalence of AMS was $1.24 \%$ higher in women than in men [24]. There are several hypotheses to explain this result in relation to estrogen and testosterone hormones. Estrogen increases the vascular endothelial growth factor, which leads to exudation of tissue fluid and, consequently, cranial hypertension. Furthermore, it is also known to lower the threshold of the antidiuretic hormone; therefore, estrogen leads to fluid retention. In contrast, testosterone promotes erythropoiesis by increasing erythropoietin levels, thereby increasing the concentration of red blood cells in the serum and enhancing the capacity to carry oxygen to the cells.

Age (>35 years)

Most studies describe that going to high altitudes is not recommended at a young age. None of the participants were younger than 18 years old, as it was an exclusion criterion for the articles; therefore, differences for individuals below 18 years have not been studied.

No significant differences were found in the LLS meta-analysis with respect to age. This could be due to the small age range, as the average age was similar in all studies, and extreme ages were not included. 
Overall, the HS group results were significant, showing age $>35$ years as a protective factor for AMS. This could be due to the experience of the older climbers, as they have had other mountaineering experiences, they know when to descend before suffering from AMS or when to treat symptoms of AMS. Another factor could be brain compliance, as it is higher in older people; therefore, brain edema would be less symptomatic.

The results of $\mathrm{Wu}$ et al. [25] coincide with our results in the LLS group, as no statistically significant results were obtained in relation to age. However, the HS group analysis is contradictory to the results of these studies, indicating the great variability of results related to this variable that could be due to the heterogeneity of the included studies.

\section{Smoking}

Non-smokers were more susceptible to AMS. This does not mean that smoking is recommended for high-altitude climbing, as it has worse secondary effects. We suggest that this could be attributed to a lower oxygenation process. Smokers are used to inhaling smoke and more $\mathrm{CO}_{2}$ when smoking, so they are used to lower $\mathrm{O}_{2}$ levels in their daily lives. In this context, it has been reported that cigarette smoke can reversibly activate the transcription factor hypoxia-inducible factor 1 (HIF-1) and upregulate the genes dependent on HIF-1 [26]. This may lead to a higher hematocrit since when there is an oxygen need, more red blood cells are generated. Indeed, this mechanism might facilitate easier acclimatization.

In a meta-analysis by $\mathrm{Xu}$ et al., a protective association was also found between smoking and the risk of AMS. They attributed this to higher $\mathrm{CO}$ and NO levels in smokers [27].

\section{High BMI/Obesity}

This variable was not statistically significant, although in the LLS group, this variable tended to have a risk effect. This may be due to the small number of obese participants. Most of the climbers were fit or of normal weight, which may have underestimated the weight variable in the meta-analysis.

\section{Awareness}

No statistically significant result was found associated with AMS awareness, although it tended to have a protective effect. In fact, a person who is aware of the effects of AMS could be more likely to prevent AMS by taking prophylactic medication such as acetazolamide or descending rapidly when having any symptoms.

\section{Acetazolamide}


The acetazolamide effect was not statistically significant in the LLS or the HS meta-analysis, although it tended to be protective. This result is certainly controversial because there are many studies that confirm the prophylactic effect of acetazolamide [28,29], however the protective effect is not significant in this meta-analysis. It is possible that as acetazolamide is usually taken with other medications not all studies have correctly collected the use of this drug and its protective effect and that in some way masks its effect. Therefore, more specific studies should be performed.

\section{History of AMS}

A previous experience with AMS was statistically significant in both the LLS and HS groups as a risk factor. This could be attributed to individual susceptibility related to genetics or individual motivation. For example, a person who wants to reach a peak even when suffering from AMS could experience AMS during each attempt until reaching the top.

Pre-exposure

Pre-exposure for at least 2 days at a high altitude is very important for an altitude trek, as demonstrated in the LLS group. As mentioned before, acclimatization is a relevant process important to obtain a low $\mathrm{O}_{2}$ concentration at a certain altitude. Although this variable was not statistically significant in the HS group, it tended to be protective. This is in agreement with previous data, such as those that reported that high-altitude pre-exposure lasting at least 3 days within the preceding 2 months was associated with a significant lower AMS incidence during a subsequent ascent to $3402 \mathrm{~m}$ [30].

\section{Resilience}

Living at high altitudes tends to be a protective factor where people living at higher altitudes tend to have a lower prevalence of AMS. Although the results of this study were not statistically significant, a protective association could be established. In fact, this could be explained by the acclimatization process, as people living at higher altitudes are more likely to use lower levels of oxygen, and the acclimatization process could be easier for them.

\section{Rapid ascent}

Considering all the studies, no statistically significant results were found for this variable in either the LLS or HS group. This result is in line with other studies that have found that the incidence of AMS is not associated with the rate of ascent [31]. Nevertheless, it is generally thought that a slow ascent is important in preventing AMS. 
With rapid ascent, the individual does not have time to get used to the low oxygen concentration. Furthermore, the cells need more energy to work faster; therefore, they require more oxygen to obtain energy through aerobic metabolism. With rapid ascent, physical exercise intensity increases, which in relation to a low oxygen concentration, can lead to anaerobic metabolism, a less efficient process that can lead to an accumulation of metabolites.

\section{Maximum altitude}

The results in the LLS group were statistically significant for this variable, which can be explained by the incremental effect of higher altitude on AMS. However, the results of the HS group were not statistically significant. In this regard, it is thought that at higher altitudes, the $\mathrm{pO}_{2}$ is lower; therefore, the probability of suffering from AMS is higher when climbing to a higher maximum altitude.

One of the limitations of the study is the small number of studies that met all the criteria and measured all the variables, reducing the statistical robustness of the meta-analysis. This limitation is even greater in the case of the HS group, where there were far fewer studies that used it for the assessment of AMS. However, having carried out the meta-analysis with both scores is a great advantage since similar analysis is rare and it provides an analysis of variables with two different ways of assessing the outcome of AMS.

According to the statistically significant results from this study, several risk factors should be considered when going to high altitudes. For example, several factors have been associated with a higher risk of AMS, such as young age, non-smoking status, previous experience of AMS, non-acclimatization, and a high maximum altitude. Furthermore, some protective factors have been associated with AMS, such as older age, smoking, no history of AMS, acclimatization, and hiking to a low maximum altitude. More studies should be performed to clarify the association of inconclusive variables with the probability of suffering from AMS.

\section{Declarations}

Funding

This work has been developed by members of the University of Navarra Mountain Club from the Sport service and funding with a grant of Olympic Studies Center of the University of Navarra, Spain. 
Author's contributions

Conception and design: Sergio Recalde, Fermín Milagro, Ricardo Ibañez, Laura García-Garcia and Manuel Cires. Data collection: Leire Alargunsoro. Analysis and interpretation: Leire Alargunsoro, Sergio Recalde, Fermín Milagro. Manuscript preparation: Leire Alargunsoro, Andrea Villegas, Victor J. Sáez, Fermín Milagro, Ricardo Ibañez, Sergio Recalde.

Acknowledgements:

Authors would like to thank to Dr. Enrique Maraví for their invaluable help in the development of this project. Also, they want to thank the rest of the team of University of Navarra Mountain Club and specially the technician work of Carlos Irisarri and Francisco Gonzalez and the English revision work of Editage.

\section{References}

1. Goitia A, Aguirre J, De Prado N, Estellés A, Zurita A, Millán J. Tus pacientes también vuelan. Aspectos médicos de la aviación comercial. Semergen. 1999;25:806-17.

2. Hoiland RL, Howe CA, Coombs GB, Ainslie PN. Ventilatory and cerebrovascular regulation and integration at high-altitude. Clinical Autonomic Research. Springer Berlin Heidelberg; 2018;28:423-35.

3. Naeije R. Physiological adaptation of the cardiovascular system to high altitude. Progress in Cardiovascular Diseases. Elsevier Inc.; 2010;52:456-66.

4. Central H. Venegas Perez P . - Bases Biológicas del Entrenamiento en Altitud Bases Biológicas del Entrenamiento en Altitud 5to . Congreso Virtual de Cardiologia Venegas Perez P . - Bases Biológicas del Entrenamiento en Altitud 5to . Congreso Virtual de Cardiologia. 1968;

5. Dufrense C. Enciclopedia de salud y seguridad en el trabajo. 1998;

6. Hackett, Peter H., MD ARCR. High-Altitud Illness. New England Journal of Medicine. 2001;345:107-14.

7. Imray C, Wright A, Subudhi A, Roach R. Acute mountain sickness: Pathophysiology, prevention, and treatment. Progress in Cardiovascular Diseases. Elsevier Inc.; 2010;52:467-84. 8. Roeggla G, Roeggla M, Podolsky A, Wagner A, Laggner AN. How can acute mountain sickness 
be quantified at moderate altitude? Journal of the Royal Society of Medicine. 1996;89:141-3. 9. Urdampilleta A, Martínez-Sanz JM. Y Planificación Dietética En El Alpinismo. 2012;35-66. 10. McDevitt M, McIntosh SE, Rodway G, Peelay J, Adams DL, Kayser B. Risk determinants of acute mountain sickness in trekkers in the Nepali Himalaya: A 24-year follow-up. Wilderness and Environmental Medicine. Elsevier; 2014;25:152-9.

11. Gonggalanzi, Labasangzhu, Nafstad P, Stigum H, Wu T, Haldorsen OD, et al. Acute mountain sickness among tourists visiting the high-altitude city of Lhasa at $3658 \mathrm{~m}$ above sea level: A cross-sectional study. Archives of Public Health. Archives of Public Health; 2016;74:1-7.

12. Maclnnis MJ, Carter EA, Freeman MG, Pandit BP, Siwakoti A, Subedi A, et al. A Prospective Epidemiological Study of Acute Mountain Sickness in Nepalese Pilgrims Ascending to High Altitude (4380 m). PLoS ONE. 2013;8:1-7.

13. Croughs M, Van Gompel A, Van Den Ende J. Acute mountain sickness in travelers who consulted a pre-travel clinic. Journal of Travel Medicine. 2011;18:337-43.

14. Sánchez-Mascuñano A, Masuet-Aumatell C, Morchón-Ramos S, Ramon JM. Relationship of altitude mountain sickness and smoking: A Catalan traveller's cohort study. BMJ Open. 2017;7:1-7.

15. Yang SL, Ibrahim NAF, Jenarun G, Liew HB. Incidence and Determinants of Acute Mountain Sickness in Mount Kinabalu, Malaysia. High Altitude Medicine and Biology. 2020;21:265-72.

16. Wu TY, Ding SQ, Liu JL, Jia JH, Chai ZC, Dai RC. Who are more at risk for acute mountain sickness: A prospective study in Qinghai-Tibet railroad construction workers on Mt. Tanggula. Chinese Medical Journal. 2012;125:1393-400.

17. Davies AJ, Kalson NS, Stokes S, Earl MD, Whitehead AG, Frost H, et al. Determinants of summiting success and acute mountain sickness on Mt kilimanjaro (5895 m). Wilderness and Environmental Medicine. Elsevier; 2009;20:311-7.

18. Timothy E. Burdick, MD; Reed Brozen M, From. Wilderness Event Medicine Timothy. Wilderness and Environmental Medicine. Elsevier; 2003;14:236-9.

19. Weng YM, Chiu YH, Lynn JJ, Li WC, Wang SH, Kao WF, et al. Different duration of highaltitude pre-exposure associated with the incidence of acute mountain sickness on Jade Mountain. American Journal of Emergency Medicine. Elsevier Inc.; 2013;31:1113-7.

20. Karinen $\mathrm{H}$, Peltonen J, Tikkanen $\mathrm{H}$. Prevalence of acute mountain sickness among finnish 
trekkers on Mount Kilimanjaro, Tanzania: An observational study. High Altitude Medicine and Biology. 2008;9:301-6.

21. Mahomed Z, Martin D, Gilbert E, Grant C, Patricios J, Motara F. Identifying risk factors that contribute to acute mountain sickness. South African Journal of Sports Medicine. 2015;27:826.

22. Santantonio M, Chapplain JM, Tattevin P, Leroy H, Mener E, Gangneux JP, et al. Prevalence of and risk factors for acute mountain sickness among a cohort of high-altitude travellers who received pre-travel counselling. Travel Medicine and Infectious Disease. 2014;12:534-40.

23. Rathat C, Richalet J-P, Herry J-P, Larmignat P, Thieme G, Stuttgart V, et al. S76-S78 Larmignat, Detection of High-Risk Subjects for High Alti-tude Diseases. mt j Sports Med. 1992.

24. Hou YP, Wu JL, Tan C, Chen Y, Guo R, Luo YJ. Sex-based differences in the prevalence of acute mountain sickness: A meta-analysis. Military Medical Research. Military Medical Research; 2019;6.

25. Wu Y, Zhang C, Chen Y, Luo YJ. Association between acute mountain sickness (AMS) and age: A meta-analysis. Military Medical Research. 2018;5:1-8.

26. Daijo H, Hoshino Y, Kai S, Suzuki K, Nishi K, Matsuo Y, et al. Cigarette smoke reversibly activates hypoxia-inducible factor 1 in a reactive oxygen species-dependent manner. Scientific Reports [Internet]. 2016;6:34424. Available from: http://www.nature.com/articles/srep34424 27. Xu C, Lu HX, Wang YX, Chen Y, Yang S hong, Luo YJ. Association between smoking and the risk of acute mountain sickness: A meta-analysis of observational studies. Military Medical Research. Military Medical Research; 2016;3.

28. Gertsch JH, Basnyat B, Johnson EW, Onopa J, Holck PS. Randomised, double blind, placebo controlled comparison of ginkgo biloba and acetazolamide for prevention of acute mountain sickness among Himalayan trekkers: the prevention of high altitude illness trial (PHAIT). BMJ (Clinical research ed.) [Internet]. 2004;328:797. Available from:

http://www.ncbi.nlm.nih.gov/pubmed/15070635

29. Shlim DR. The use of acetazolamide for the prevention of high-altitude illness. Journal of travel medicine [Internet]. 2020;27. Available from:

http://www.ncbi.nlm.nih.gov/pubmed/31897486

30. Weng Y-M, Chiu Y-H, Lynn J-J, Li W-C, Wang S-H, Kao W-F, et al. Different duration of highaltitude pre-exposure associated with the incidence of acute mountain sickness on Jade 
Mountain. The American journal of emergency medicine [Internet]. 2013;31:1113-7. Available from: http://www.ncbi.nlm.nih.gov/pubmed/23688567

31. Hsu T-Y, Weng Y-M, Chiu Y-H, Li W-C, Chen P-Y, Wang S-H, et al. Rate of ascent and acute mountain sickness at high altitude. Clinical journal of sport medicine : official journal of the Canadian Academy of Sport Medicine [Internet]. 2015;25:95-104. Available from:

http://www.ncbi.nlm.nih.gov/pubmed/24751723

Figures, tables and additional files

\section{Abbreviations}

AMS: Acute Mountain Sickness.

HS: Hackett's Score.

LLS: Lake Louise Score.

OR: Odds Ratio.

Competing interests

There is not conflict of interest to declare.

\section{Figure Legends}

Figure 1. Flow-chard of the valid studies included in the meta-analysis.

Figure 2 . Forest plot analysis of principal variables measured by the LLS. A. FP of the smoking effect in the AMS. B. FP of the history of previous AMS. C. FP of the pre-exposure effect in the AMS. D. FP of the maximum altitude effect in the AMS.

Figure 3. Forest plot analysis of principal variables measured by the HS. A. FP of the age effect in the AMS. B. FP of the history of previous AMS.

Figure 4. Funnel plot of articles included in the Forest plot in the LLS. A. Funnel plot of five articles measuring the smoking effect on the AMS. B. Funnel plot of the five articles measuring the history of previous AMS. C. Funnel plot of five articles measuring pre-exposure. D. Funnel plot of three articles measuring maximum altitude effect on the AMS Loggrr: logarithm of the relative risk; s.e. of logrr: standard error of the logarithm of the relative risk.

Figure 5. Funnel plot of articles included in the Forest plot in the HS. A. Funnel plot of three articles measuring age effect on the AMS. B. Funnel plot of two articles measuring the history of previous AMS. Loggrr: logarithm of the relative risk; s.e. of logrr: standard error of the logarithm of the relative risk. 


\section{Figures}

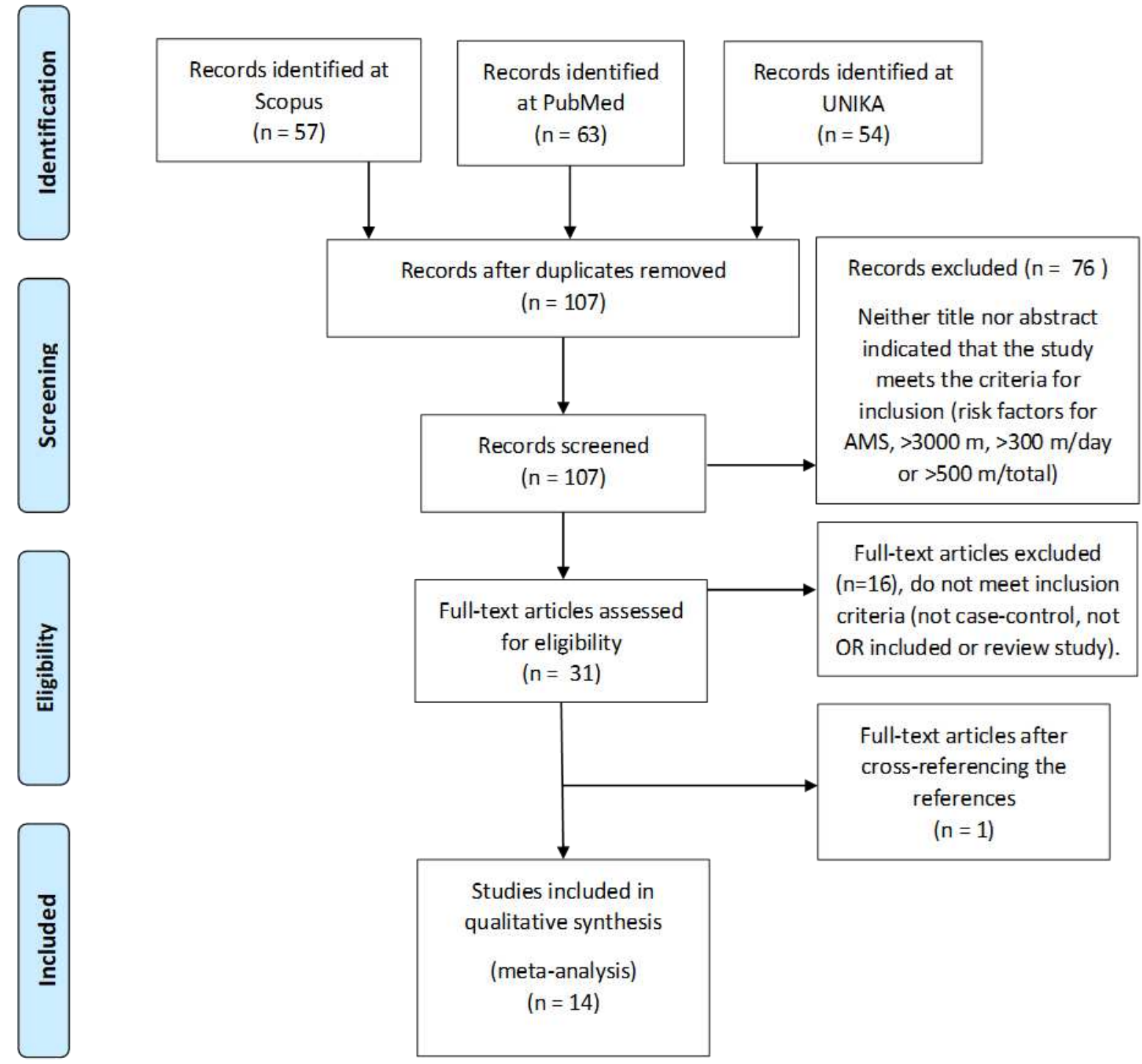

Figure 1. Flow-chard of the valid studies included in the meta-analysis. 
A

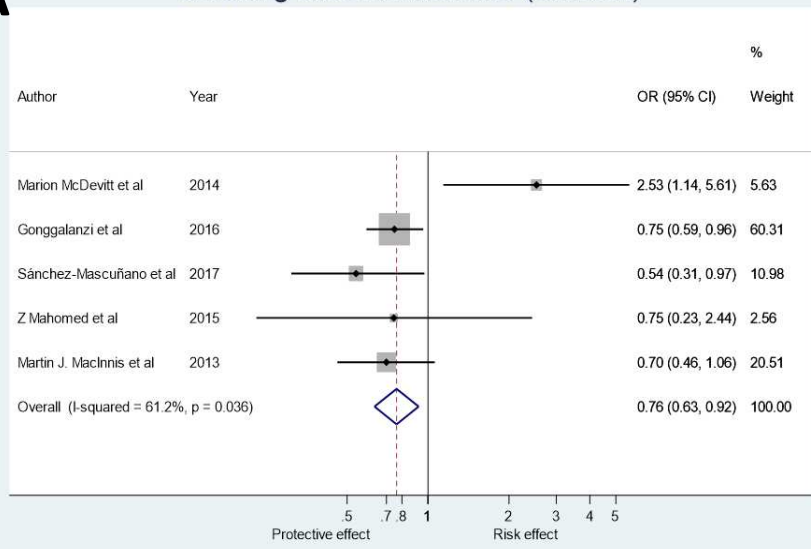

C

Pre-exposure in the AMS (>2 days)

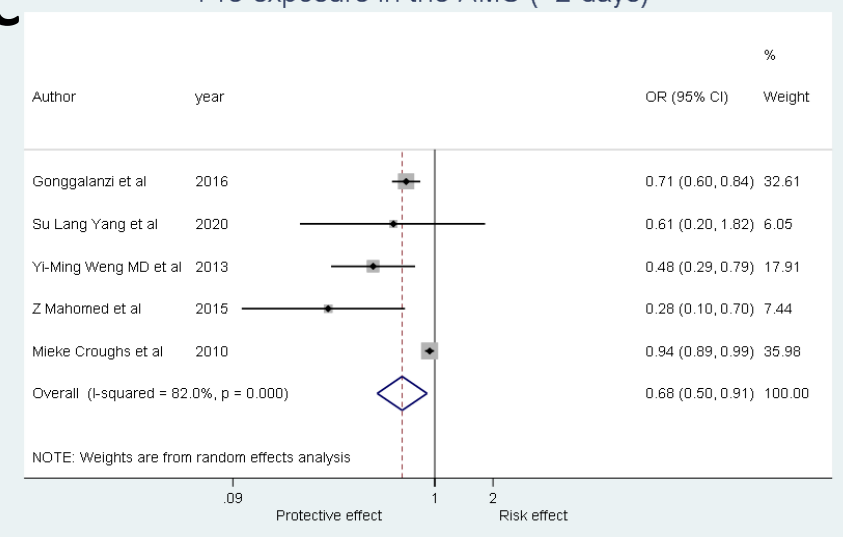

B

History of AMS in the AMS (Previous AMS)

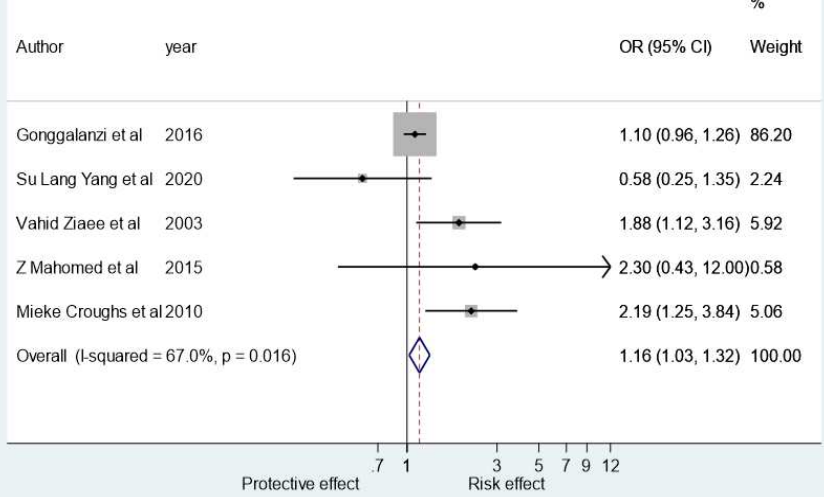

D Maximum altitude effect in the AMS $(>2400 \mathrm{~m})$

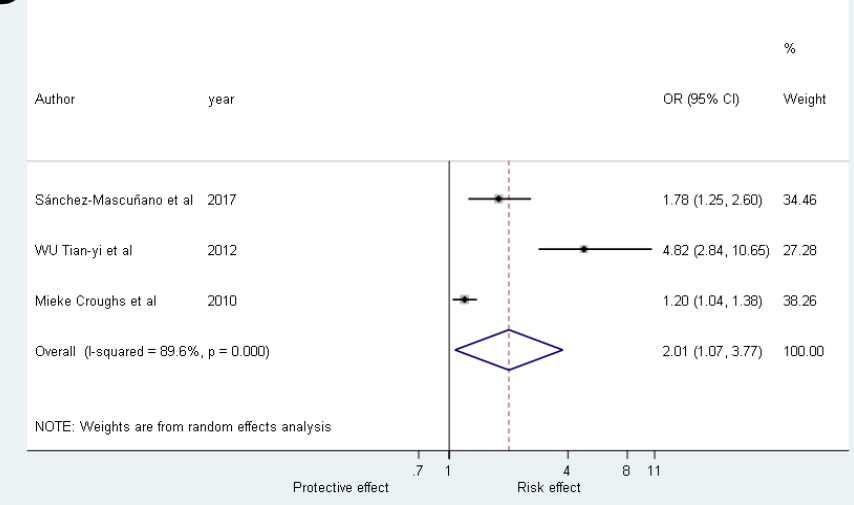

Figure 2 . Forest plot analysis of principal variables measured by the LLS. A. FP of the smoking effect in the AMS. B. FP of the history of previous AMS. C. FP of the pre-exposure effect in the AMS. D. FP of the maximum altitude effect in the AMS. 


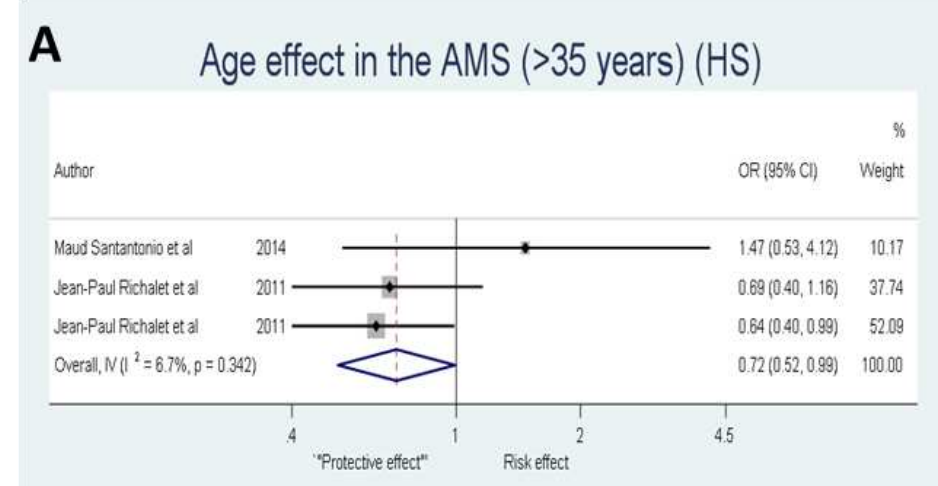

B History of AMS effect in the AMS (Previous AMS)

auther

OR $(95 \% \mathrm{Cl}) \quad$ Weight

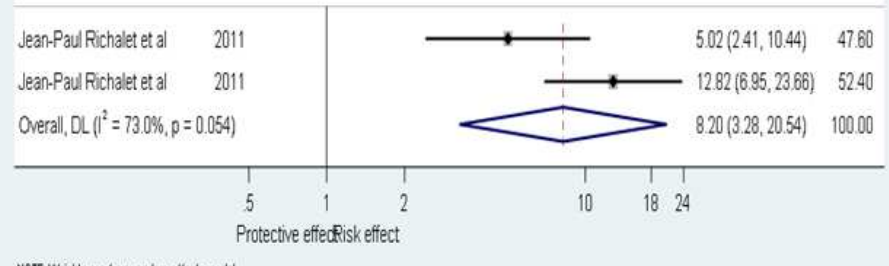

NOTE Weyts are tron randonetfects noses

Figure 3. Forest plot analysis of principal variables measured by the HS. A. FP of the age effect in the AMS. B. FP of the history of previous AMS. 

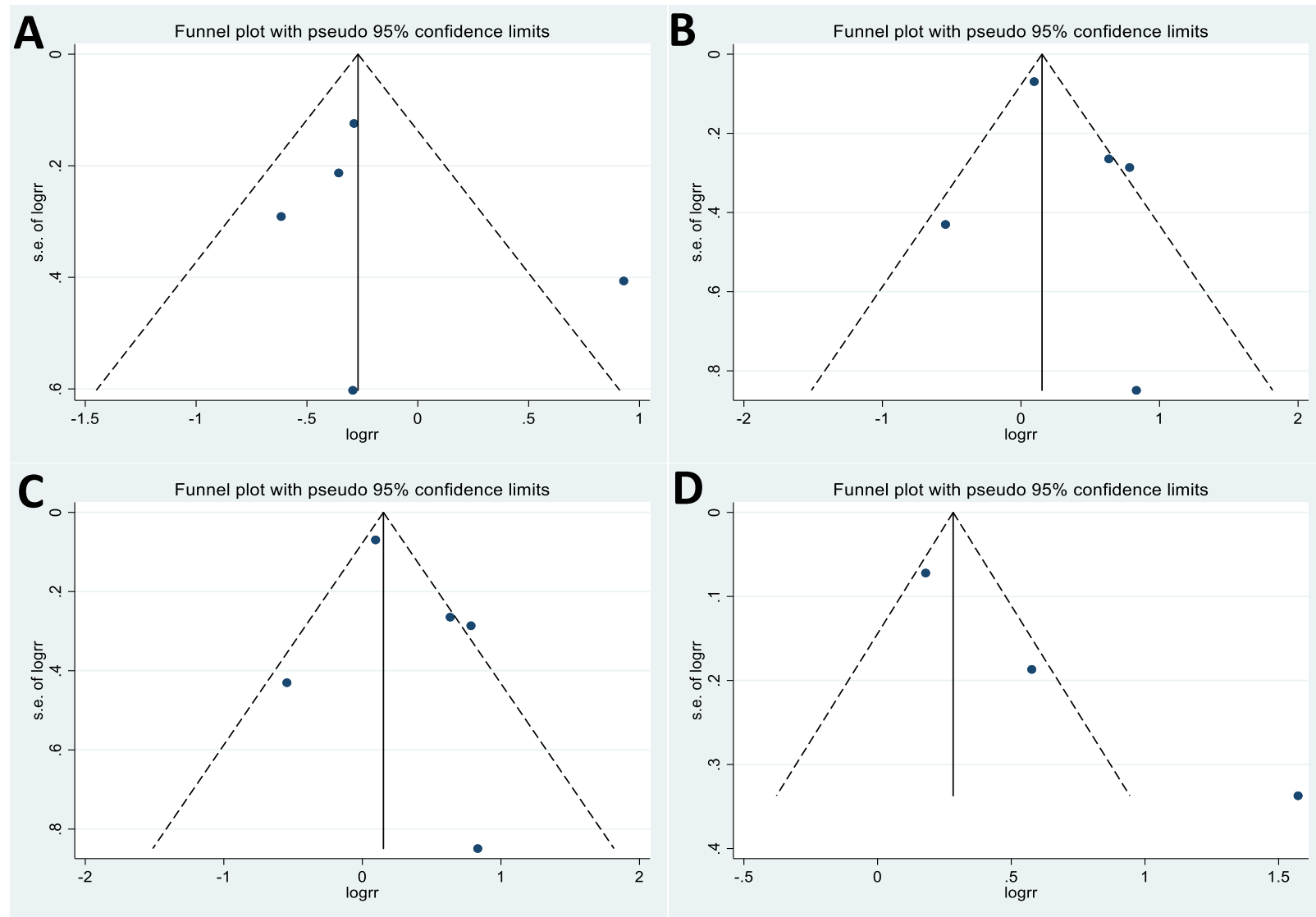

Figure 4. Funnel plot of articles included in the Forest plot in the LLS. A. Funnel plot of five articles measuring the smoking effect on the AMS. B. Funnel plot of the five articles measuring the history of previous AMS. C. Funnel plot of five articles measuring pre-exposure. D. Funnel plot of three articles measuring maximum altitude effect on the AMS Loggrr: logarithm of the relative risk; s.e. of logrr: standard error of the logarithm of the relative risk. 

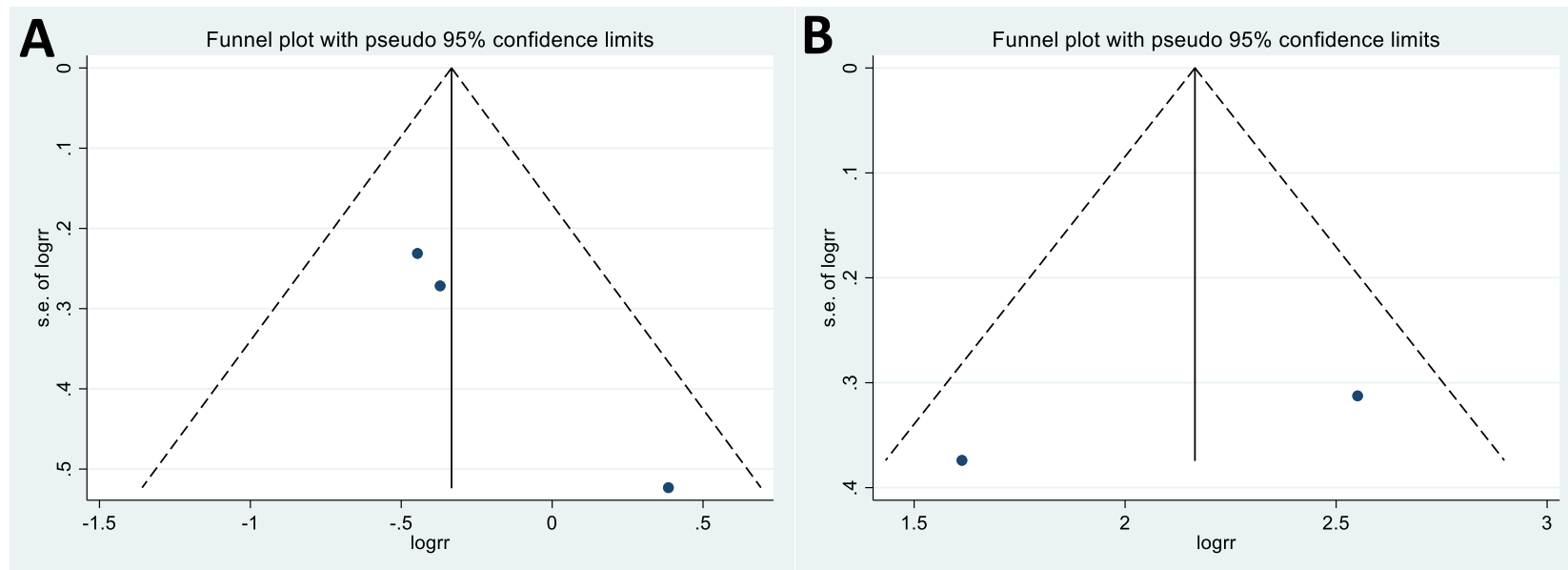

Figure 5. Funnel plot of articles included in the Forest plot in the HS. A. Funnel plot of three articles measuring age effect on the AMS. B. Funnel plot of two articles measuring the history of previous AMS. Loggrr: logarithm of the relative risk; s.e. of logrr: standard error of the logarithm of the relative risk. 